\title{
Yoga, Mindful Eating, and Weight Management
}

\author{
Stephanie Bryan ${ }^{1,{ }^{*}}$, Raju Parasher ${ }^{2}$, Terrence Cahil $^{2}$ and P.T. Genevieve Pinto Zipp ${ }^{2}$ \\ ${ }^{1}$ Saint Peter's University, USA \\ ${ }^{2}$ Seton Hall University, USA
}

\begin{abstract}
Physical inactivity, overweight, and obesity are serious issues plaguing the American public. The extent to which regular yoga participation may be associated with the adoption and maintenance of health enhancing behaviors necessitates further investigation. Through a mixed method of inquiry, this study investigated the exercise and eating habits of adults who participate in yoga on a regular basis exploring facets of mindful eating, exercise habits, and body mass index. Survey packets were distributed across seven yoga studios and fitness facilities in central New Jersey; 87 adults with a mean age of 47 years self-selected to participate. Quantitative and qualitative data were collected including a Mindful Eating Questionnaire, a 7-Day Physical Activity Recall, height and weight, yoga tenure recorded in months/years of consistent yoga participation, and average daily fruit and vegetable intake. Results showed that mindful eating was inversely correlated with Body Mass Index (BMI) and that $72 \%$ of the yoga participants had a BMI of 24.9 or less, placing them in the normal weight category. A significant difference existed in mindful eating score relative to yoga tenure and vegetable and fruit intake relative to yoga tenure. Participants reported a mean of 239 minutes of weekly exercise other than yoga participation. Qualitative data were collected through two open-ended questions to ascertain the participants' perceptions of yoga and their health-related behaviors; the data revealed that $87 \%$ of participants felt yoga enhanced their exercise adherence and $91 \%$ reported yoga promoted the adoption of positive health habits. The results suggest that yoga participation is associated with mindful eating and the adoption and maintenance of other positive health-related outcomes such as regular physical activity and weight management.
\end{abstract}

Keywords: Physical inactivity, weight management, mindful eating, yoga, mind/body.

\section{INTRODUCTION}

Scientific literature suggests that sustained cardiovascular activity and restricted caloric intake can result in a decreased body weight, a reduction in the incidence of disease, and an improvement in the quality of life [1-3]. Achieving permanent change in eating and physical activity behaviors; however, remains a significant issue in the United States, especially among the $68 \%$ of adults who are overweight and/or obese [4]. Barriers to consistent physical activity include poor exercise self-efficacy [5], unpleasant exercise feeling-states [6], lack of social support [7], and poor self-regulation abilities [8]. Exercise self-efficacy involves the belief that one can regularly carry out exercise as a matter of course [9]. In Albert Bandura's writings on self-efficacy, he suggests that how a person feels affects what they think and that what they think affects what they do [10]. Generally, mindfulness is the ability to attend to thoughts, feelings, and emotions as they arise, promoting awareness in the present state. Mindfulness results from the regulation of focus or awareness which is essentially a learned skill; mindfulness may be viewed as the selfregulation of attention [11]. Mindful meditation is a common component of group yoga classes often generating an essence of non-judgment, current

*Address correspondence to this author at the Saint Peter's University, USA; E-mail: yogastudy@aol.com acceptance, self-awareness, and peacefulness. Mindful meditation in a yoga class environment provides an opportunity for yoga participants to learn and "practice" the skill of mindfulness. Qualitative research has demonstrated that yoga participants report an increased awareness of their feelings, a heightened attention to their eating patterns, an improved confidence in their ability to exercise, and an increased capacity to manage stress as a result of their yoga experience [12].

A common method of prescribing exercise includes attention to the mode, intensity, and duration of movement with little attention to how a person feels during and after the activity. An exercise induced feeling inventory captures a participant's immediate feeling-state post activity and may provide a possible link between how one feels during and after exercising and the perpetuation of exercise behaviors. Previously sedentary adults who participated in yoga over a tenweek period reported "feeling strongly" that they were peaceful, happy, upbeat, and enthusiastic while "feeling slightly" tired, fatigued, and worn out. These participants made significant improvements in their adherence to exercise as evidenced by the post-test data collection, while also reporting a heightened awareness of their eating behaviors [12].

An emerging body of evidence supports the creation of positive feeling states and an awareness of feeling states as two powerful contributors to the improvement 
of health-related behaviors. Eating behaviors are likewise impacted by an increased awareness of feelings; mindful eating is considered an awareness of feelings and sensations in relation to eating and the ability to be a mindful eater is associated with yoga practioners [13]. In a five-day weight loss program incorporating Kripalu yoga, significant improvements in nutrition behaviors were achieved [14]. Additionally, measures of mindfulness in everyday life were predictive of physical activity and fruit and vegetable intake in a volunteer population at a mid-western University [15]. Research conducted by Kristal, Littman, Benitez \& White [16] investigated the health-related behaviors of middle-aged adults who participated in four or more years of yoga in comparison to individuals who did not participate in yoga. They found that yoga is associated with attenuated weight gain, increased consumption of fruits and vegetables, and higher energy out-put through physical activity beyond that of yoga participation. Sustainable health behaviors such as mindful eating and exercise adherence may be impacted by participation in an exercise program such as yoga, which provides an increased attention to current feeling states through mindfulness meditation.

The current investigation expands the body of knowledge surrounding the mind/body effects of yoga by examining the behaviors of yoga participants with yoga tenure as a categorical variable. Lifestyle behavior enhancement is essential to the maintenance of optimal weight and eating patterns in the fight against overweight and obesity. Mindfulness meditation, integral to yoga, results in a sense of mind/body connection and awareness that may make a significant contribution to self-regulation abilities such as adherence to exercise and eating patterns. Ultimately, yoga may be a productive intervention towards the development of health-enhancing behaviors. Equally as important, yoga can be a relatively inexpensive, self-paced, non-competitive mind/body activity that may be easily provided in a variety of environments such as school-based physical education, corporate fitness, commercial and community fitness facilities.

\section{SUBJECTS AND METHODS}

\section{Subjects and Screening Procedures}

Apparently healthy males and females 18 years or older who participate in yoga classes at least once per week were recruited to participate in the study. Yoga participation at least once per week was defined as one or more classes per week on a weekly basis attended in a commercial or recreation facility. There were no restrictions placed on the duration of time in weeks, months and/or years of participation. Participants were excluded if they were pregnant, only participated in yoga privately, or attended yoga classes on an inconsistent basis. Survey packets were distributed in seven commercial fitness and yoga studios throughout New Jersey; they were left in common areas and accompanied by a return receptacle. The outside of the survey packet was affixed with the solicitation and informed consent letter that received institutional review board (IRB) approval from Seton Hall University's IRB. Surveys were distributed to all seven locations, and completed surveys were retrieved once per week for a period of six weeks. A total of three hundred surveys were dispensed to the research sites.

\section{Research Design and Variables}

This study utilized an exploratory design including both quantitative and qualitative methods of data collection. All data were collected via a survey packet at one sitting. Valid instruments were used to measure variables including the amount of weekly physical activity participation as measured by 7-Day Physical Activity Recall [17] and mindful eating as measured by the Mindful Eating Questionnaire [13]. Data on the average daily intake of fruits and vegetables were collected as well as the amount of time spent participating in exercise per week other than yoga. Also, two open-ended questions pertaining to the yoga experience were included. Yoga tenure was the final variable, measuring the amount of time in total months an individual had consistently participated in yoga.

The 7-Day Physical Activity Recall measures the amount of moderate and vigorous physical activity performed in the previous week in hours; moderate activity includes activities such as gardening and walking, while vigorous activity includes activities such as running and singles tennis. The mindful eating questionnaire (MEQ) is a 28-item questionnaire that assesses an individual's awareness of sensations, emotions, motivations, and responses to eating. There are four domains represented within the questionnaire: dis-inhibition, awareness, external cues, emotional responses and distraction. Responses are gathered in a four point scale ranging from never/rarely to usually/always. A MEQ score of 2.92 has been associated with mindful eating practices in previous research [13]. 
The two open-ended questions were designed by the researchers and used in previous research to further delve in to the yoga participants' perceptions of yoga and its impact on their lifestyle behaviors [12]. The first question was: "Have any of your health behaviors changed over the course of your yoga experience in a way that may be related to your participation in yoga? If yes, please describe which behaviors you believe have changed and how." The second question was: "Based upon your participation in yoga classes, do you believe yoga has had an impact on your ability to adhere to an exercise program? If so, please note why." The demographic and personal data gathered included: age, gender, height, weight, ethnicity, level of education, length of participation in yoga classes expressed in months and years, number of yoga classes currently taken per week, approximate number of yoga teachers attended throughout yoga experience, servings of fruits and vegetables eaten per day, other forms of exercise performed regularly, amount of time spent during yoga class on meditation/relaxation, and the amount of time spent during yoga class performing postures.

\section{Analysis}

The research team analyzed data using SPSS version 18. Yoga tenure data were transformed into three groups: (1) participants who have taken yoga for 1-24 months, (2) participants who have taken yoga from 25-74 months, and (3) participants who have taken yoga for 75 months and beyond. The researchers used an analysis of variance to uncover any differences in the following variables based on yoga tenure: mindful eating, fruit and vegetable intake, and exercise adherence. According to the mindful eating survey instructions, the researchers tabulated the mindful eating summary scores and used descriptive statistics to uncover the mindful eating score range, mean, and mode. Body mass index (BMI) was calculated using the participant's self-reported height and weight data. With all of the participants measured as one group, correlational analysis assessed whether there was a relationship between $\mathrm{BMI}$ and mindful eating as well as exercise adherence and yoga tenure. Finally, the qualitative data were analyzed for emerging themes and coded.

\section{RESULTS}

Participants were enrolled in the study between December and February from three fitness centers offering group yoga classes and four yoga studios. The completed surveys created a sample consisting of 87 adults, 71 women and 16 men ages between 18 and 78 , with a mean age 47 . Demographic and personal data for the participants are reported in Tables $\mathbf{1}$ and $\mathbf{2}$. After data transformation of yoga tenure (amount of time in months performing yoga) into groups, the sample size for each group is 32 adults participating in yoga from 1-24 months, 26 adults for 25-74 months and 28 adults for 75 months and beyond.

\section{Quantitative Outcomes}

One-way ANOVA overall test of the means did not uncover a significant difference in exercise adherence using the 7-Day Physical Activity Recall and the three yoga tenure groups. Further correlational analysis using Pearson's correlation coefficient revealed a significant but weak linear relationship $r=.22, p<.02$ between total yoga tenure and adherence to exercise. For these data, the mean (SD) for yoga tenure is 65.43 months (77.23) and physical activity recall is 9.08 hours (7.07). The overall test of the means using a one-way ANOVA was significant for mindful eating and yoga tenure in groups; $F(2,80)=3.633 p<.031$. The Bonferroni method was used to perform pairwise comparisons indicating at the overall 0.05 level that the first grouping was significantly different from the second grouping $(M=2.59, S D=.1056)$; see Figure 1 . The overall test of the means using a one-way ANOVA was significant for consumption of fruits and vegetables and yoga tenure in groups, $F(2,84)=4.527 p<.014$.

Table 1: Demographic Data

\begin{tabular}{|c|c|c|c|c|}
\hline Age & Range 18-78 & Mean 47 & & \\
\hline Gender & Female $\mathrm{N}=71,81.6 \%$ & Male $\mathrm{N}=16,18.4 \%$ & & \\
\hline Ethnicity & White $\mathrm{N}=66,75 \%$ & Asian $\mathrm{N}=11,12.6 \%$ & African American $\mathrm{N}=1$ & \\
\hline Ethnicity & $\begin{array}{c}\text { Indian } \mathrm{N}=3 \\
\text { Hispanic/Latino } \mathrm{N}=1\end{array}$ & $\begin{array}{l}\text { Native Hawaiian/ Pacific } \\
\text { Islander } \mathrm{N}=3\end{array}$ & No answer $=2$ & \\
\hline Education & $\begin{array}{c}\text { High School N=7 } \\
\text { Two-year College N=6 }\end{array}$ & Four-year College $\mathrm{N}=33$ & Master's Degree $\mathrm{N}=32$ & Doctorate $\mathrm{N}=9$ \\
\hline
\end{tabular}


Table 2: Descriptive Statistics for Personal Data

\begin{tabular}{|c|c|c|c|}
\hline & Range & Mean & Standard Deviation \\
\hline BMI & $17.2-40.2$ & 23.18 & 3.72 \\
\hline Number of Yoga Teachers & $2-60$ & 12.24 & 8.01 \\
\hline Yoga Classes Per Week & $1-7$ & 2.67 & 1.66 \\
\hline Time Performing Postures in Minutes & $15-90$ & 52.08 & 14.75 \\
\hline Exercise Other Than Yoga in Minutes & $0-585$ & 239.70 & 158.77 \\
\hline Servings of Fruits and Vegetables Daily (1/2cup) & $1-12$ & 5.06 & 2.66 \\
\hline
\end{tabular}

The Bonferroni method was used to perform pairwise comparisons indicating at the overall 0.05 level that the second grouping is significantly different from the third grouping $(M=-1.938, S D=.693)$; these results are depicted in Figure 2. The descriptive statistics, found in Table 2, reveal that on average the yoga participants experienced 10 minutes of mindfulness meditation in each yoga class and 50 minutes were spent performing yoga postures; they were involved in an average of 239 minutes of exercise per week aside from their yoga classes; and they consumed an average of 5- $1 / 2$ cup servings of fruits and vegetables daily. These favorable eating and exercising behaviors resulted in $72 \%$ of the sample scoring a BMI in the acceptable weight category of 24.9 or less and an overall mean BMI of 23.18. In addition, only $3 \%$ of participants had a BMI of 30 or more indicating obese. Finally, an analysis using Pearson's correlation coefficient indicated a significant inverse relationship between total group mindful eating and BMI $r=-.185 p<.047$; for these data the mean (SD) for mindful eating was 2.89 (.409) and for BMI was 23.18 (3.72).

\section{Qualitative Outcomes}

The yoga participants were asked two open-ended questions included in each research packet. The data were analyzed for emerging themes and coded;

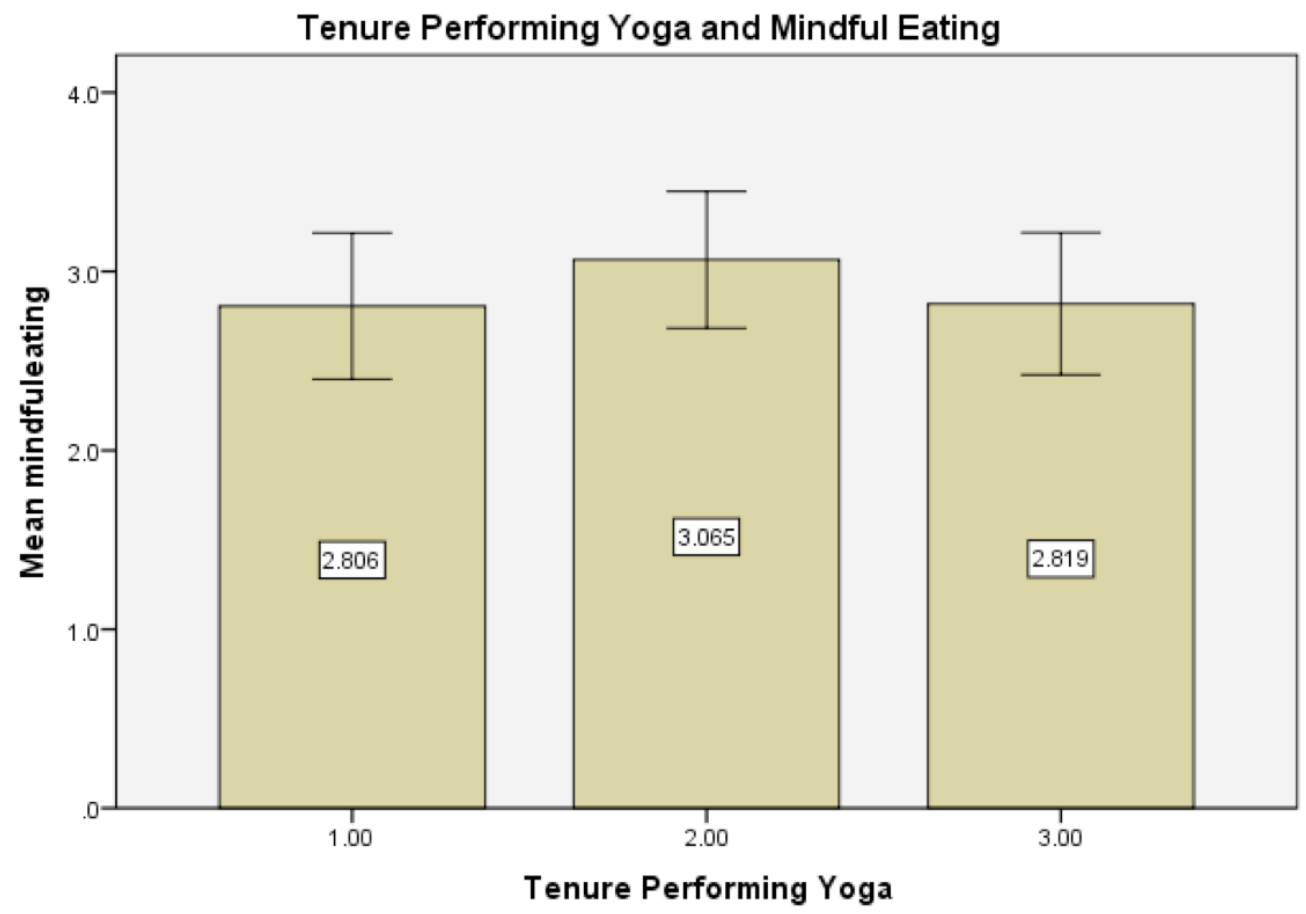

Group 1: 0-24 months Group 2: 25-74 months Group 3: 75 months and above

Figure 1: Mindful eating score relative to yoga tenure. 


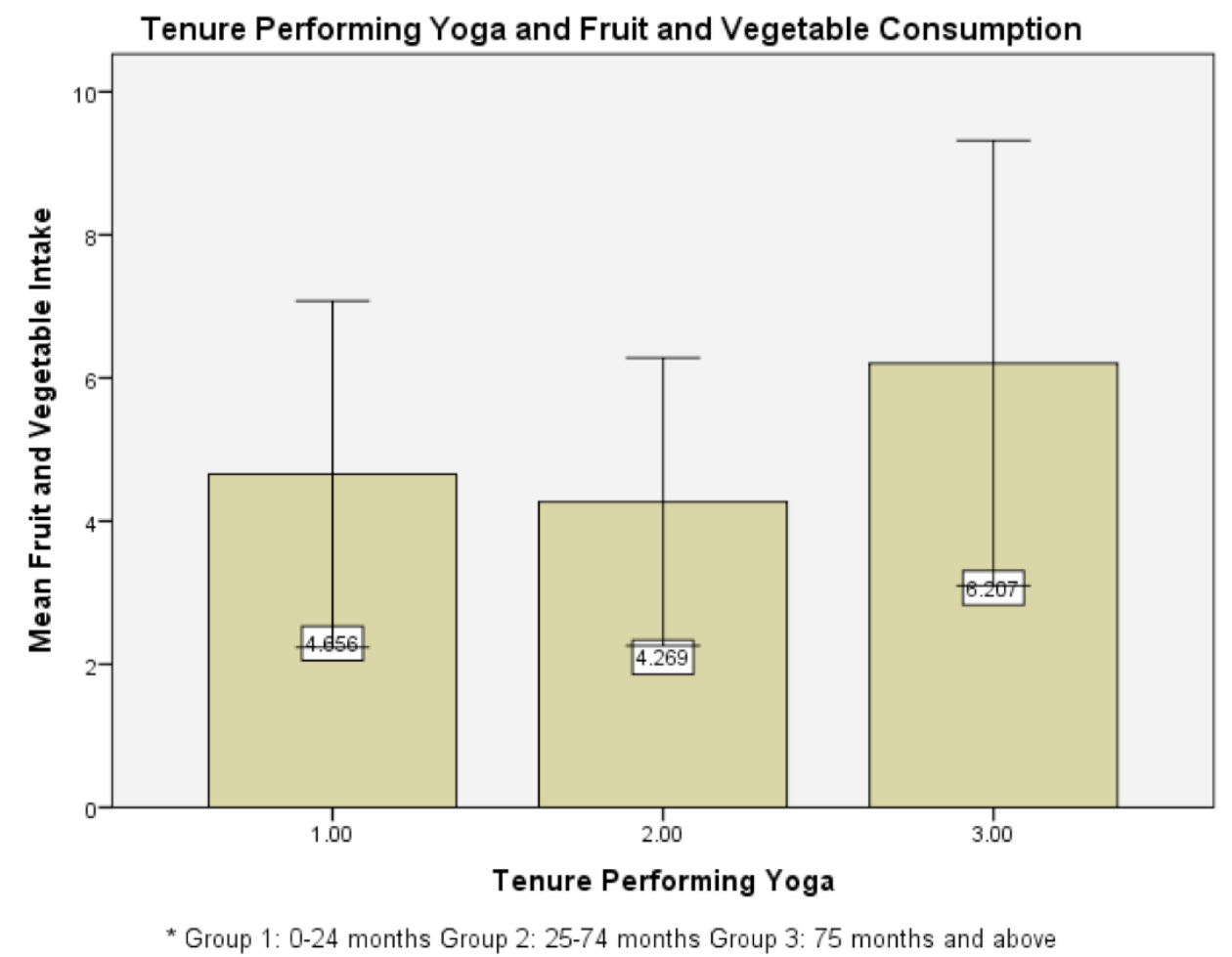

Figure 2: Fruit and vegetable intake relative to yoga tenure.

Table 3: Qualitative Data Emerging Themes, Codes, and Examples

\begin{tabular}{|c|c|c|}
\hline Emerging Themes One: Question One \\
\hline Theme: Eating behaviors & Code & Respondent Sample \\
\hline \hline \multirow{3}{*}{} & Choosing Healthier Foods & I feel like my food choices are better, don't put bad food into a healthy body \\
\cline { 2 - 3 } & Better Hydration & I am more aware of staying hydrated \\
\cline { 2 - 3 } & Eating Slowly & I eat more slowly \\
\cline { 2 - 3 } & More Mindful & I am more conscious, disciplined, and mindful with nutrition \\
\cline { 2 - 3 } & Portion Control & My eating habits have changed I pay attention to the portion of food \\
\hline
\end{tabular}

Emerging Theme Two: Question One

\begin{tabular}{|c|c|c|}
\hline Theme: Physical Behaviors & Code & Respondent Sample \\
\hline \hline \multirow{2}{*}{} & Posture & The postures in yoga remind me to walk and sit more erect \\
\cline { 2 - 3 } & Sleep & I now sleep better and longer at night with regular practice \\
\hline
\end{tabular}

\begin{tabular}{|c|c|c|}
\hline \multicolumn{3}{|c|}{ Emerging Theme Three: Question One } \\
\hline Theme: Emotional/Psychological & Code & Respondent Sample \\
\hline & Mindfulness & Yoga has opened me up to myself \\
\hline & Meditation & I started meditating daily \\
\hline & Stress Management & $\begin{array}{c}\text { I have a better overall sense of well-being and better ability to handle } \\
\text { stress }\end{array}$ \\
\hline & Health Focused & I have more focused on overall health \\
\hline & Mental/Emotional Health & I am more conscious, disciplined, and mindful of my emotions \\
\hline
\end{tabular}


(Table 3). Continued.

\begin{tabular}{|c|c|c|}
\hline Emerging Theme Four: Question One \\
\hline Theme: Physical Changes & Code & Respondent Sample \\
\hline \hline \multirow{3}{*}{} & Back Pain & Participation in yoga has eliminated lower back pain caused by a herniated disc \\
\cline { 2 - 3 } & Arthritis/Joint Pain & If I miss the pain in my knees returns and I get very stiff and uncomfortable \\
\cline { 2 - 3 } & Health/Fitness & Have gained flexibility and strength \\
\hline
\end{tabular}

\begin{tabular}{|l|c|c|}
\hline \multicolumn{2}{|l|}{ Emerging Theme One: Question Two } \\
\hline Theme: Desire to Keep Exercising & Code & Respondent Sample \\
\hline \hline \multirow{2}{*}{} & Exercise Frequency & $\begin{array}{c}\text { Yoga has and does help me to get to the gym more frequently and keep up } \\
\text { my walking each day }\end{array}$ \\
\cline { 2 - 3 } & Class Structure & $\begin{array}{c}\text { Since participating in yoga classes, it has become easier to adhere to a } \\
\text { program versus attempting to exercise on my own }\end{array}$ \\
\cline { 2 - 3 } & Adherence & $\begin{array}{c}\text { I started getting back in to shape by taking yoga. I've since joined a gym and } \\
\text { have made regular exercise a part of my life }\end{array}$ \\
\hline
\end{tabular}

Emerging Theme Two: Question Two

\begin{tabular}{|l|c|c|}
\hline Theme: Emotional/Psychological & Code & Respondent Sample \\
\hline \hline \multirow{2}{*}{} & Injury Prevention & Yes, it kept me from injuring myself. I have back problems \\
\cline { 2 - 3 } & Improved Fitness & More fit because of yoga \\
\cline { 2 - 3 } & Physique & $\begin{array}{c}\text { Seeing a change in my physical appearance has kept me on an exercise } \\
\text { program }\end{array}$ \\
\hline
\end{tabular}

\begin{tabular}{|c|c|c|}
\hline \multicolumn{3}{|l|}{ Emerging Theme Three: Question Two } \\
\hline Theme: Emotional/Psychological & Code & Respondent Sample \\
\hline & Aware of Self & $\begin{array}{l}\text { Yes it helps me focus more internally, keeping me more motivated and } \\
\text { focused on myself and my health }\end{array}$ \\
\hline & $\begin{array}{l}\text { Connection with } \\
\text { Self/Body }\end{array}$ & $\begin{array}{l}\text { Yoga has given me the ability and awareness to really connect with my } \\
\text { body not just exercise....t has enhanced my relationship with myself }\end{array}$ \\
\hline
\end{tabular}

\begin{tabular}{|c|c|c|}
\hline Emerging Themes Four: Question Two \\
\hline Theme: Perceptions and Emotions & Code & Respondent Sample \\
\hline \hline \multirow{3}{*}{} & Enhanced Feelings & Enhances how I feel, impacting what I do \\
\cline { 2 - 3 } & Enjoy Community/Group & I look forward to seeing the same people and teachers \\
\cline { 2 - 4 } & Improved Self & $\begin{array}{c}\text { I find myself seeking out yoga classes when I feel as if my health } \\
\text { habits/behaviors or overall physical/ mental wellness are } \\
\text { compromised }\end{array}$ \\
\cline { 2 - 4 } & Mind-Body & $\begin{array}{c}\text { Yoga is the only exercise I've done that engages the mind as much } \\
\text { as the body }\end{array}$ \\
\hline
\end{tabular}

\begin{tabular}{|c|c|c|}
\hline Emerging Themes Five: Question Two \\
\hline Theme: Improve/Prevent Symptoms & Code & Respondent Sample \\
\hline \hline \multirow{2}{*}{} & Arthritis & $\begin{array}{c}\text { Yoga has made me more flexible and dramatically improved my range of } \\
\text { motion and stiffness from degenerative type spinal/pelvic arthritis }\end{array}$ \\
\cline { 2 - 3 } & Aging & $\begin{array}{c}\text { Until I began yoga classes the effects of aging-stiffness, balance issues, made } \\
\text { it difficult for me to do any exercise }\end{array}$ \\
\cline { 2 - 4 } & Disease/Pain & $\begin{array}{c}\text { I have several incurable degenerative diseases-chronic discomfort, low energy, } \\
\text { low stamina, and prescription meds including steroids. Yoga helps me greatly } \\
\text { under current conditions }\end{array}$ \\
\cline { 2 - 4 } & $\begin{array}{c}\text { Weight } \\
\text { Management }\end{array}$ & I have lost 50lbs since I began yoga classes \\
\hline
\end{tabular}


see Table 3. Question one was: Have any of your health behaviors changed over the course of your yoga experience in ways that may be related to your participation in yoga? In response to question one, $91 \%$ of the participants reported that yoga had impacted their health behaviors, with 39\% stating that yoga had an impact on their eating behaviors and $41 \%$ reporting changes in emotion-related behaviors. In addition, it appears that how they feel impacts their behaviors. For example: "I am able to manage my stress and anxiety better and have a different perspective in dealing with things" and "I get a feeling of well-being after a yoga class-my outlook on life improves." References to emotional regulation and improvement were prevalent in response to both openended questions, including many references on the effects of mindfulness meditation, for example: "The more able I am to practice yoga, meditation and breathing the more calm I am and less stressed." An example of a statement that suggests a trend towards mindful eating was, "I am more conscious, disciplined and mindful with nutrition." The emerging themes for question one were eating behaviors, physical behaviors, emotional/psychological, and physical changes.

Question two was: Based upon your participation in yoga classes, do you believe yoga has had an impact on your ability to adhere to an exercise program? Overall, $87 \%$ of the respondents reported that yoga impacted their ability to adhere to exercise, with $21 \%$ of the sample communicating that they had an increased desire to adhere to exercise. In addition, $31 \%$ of the sample reported emotions impacting adherence. The answers to the open ended questions provide first person data that further inform the concept that yoga is associated with exercise adherence. Some of the statements expressed by the participants in the qualitative data were, "When I improve in yoga class, then I also stay consistent with strength training and cardio classes" and "Yoga has and does help me to get to the gym more frequently and keep up my walking each day-probably attributable to this euphoric feeling after class." Further, "I started getting back in to shape by taking yoga. l've since joined a gym and have made regular exercise a part of my life." Also, (in response to question) "Yes, absolutely it helps me do other exercise more confidently." The emerging themes for question two were desire to keep exercising, physical ability, increased self-awareness impacting choices, perceptions and emotions, and improve/prevent symptoms.

\section{DISCUSSION}

Undoubtedly, the adoption and maintenance of health-enhancing behaviors is a critical issue to be addressed by health scientists [1-3]. To broaden our understanding a mixed method of data collection was employed allowing the participants to voice their feelings associated with their yoga experience while concurrently capturing a sense of their mindfulness with the mindful eating questionnaire. The responses of the yoga participants to the open ended questions tell a story of self-awareness and self-care ascribed to their yoga tenure. They credit a belief in their ability to exercise regularly, an increased sense of well-being, improvement in mood, and a reduction in stress to their yoga participation. The qualitative data repeatedly suggests a relationship between yoga and adherence to exercise, yoga and positive feeling states, and yoga and eating practices. Yoga participation was also significantly correlated with both fruit and vegetable intake and mindful eating practices. The yoga participants reported a mean of $5,1 / 2$ cup servings of fruits and vegetables daily. The USDA suggests that 2 $1 / 2$ cups of fruits and vegetables daily reduces the risk of cardiovascular disease and stroke, while also providing protection from some forms of cancer. Additionally, research supports the association between consuming five or more servings of fruits and vegetables and longevity [18-19]. In this instance, the qualitative data collected revealed an abundance of evidence indicating the synergy between yoga and improved eating habits, and yoga and an increased desire to improve nutrient intake. Statements to this end included, "I have become more mindful of what I'm eating." One might infer that the participants' BMI results reflected the participants' adherence to exercise and proper nutrition. The majority of yoga participants in the study were a healthy weight $(72 \%)$ and only $3 \%$ fell into the obese category (national average is $33.8 \%$ ), while the remainder of the yoga participants, $25 \%$, fell in to the overweight category (national average $34 \%$ ). In total, $28 \%$ of the yoga participants fell into the overweight/obese categories, while currently the national average is $68 \%$ [4]. We also found an inverse relationship between BMI and mindful eating among the participants in this study; in other words, the more mindful an eater, the lower the BMI. Comprehensively the data support previous research and current hypotheses that suggest yoga may be associated with a measure of self-regulation resulting in adherence to exercise and adequate caloric intake [12-16], while also substantiating the relationships 
between mindful eating, self-regulation, and achieving the proper weight category.

Yoga classes are organized around physical movement; however, the physical movement may be simply a vehicle for self-awareness that results in the strengthening of the whole. As one participant stated, "Yoga has impacted my ability to adhere to my exercise routine because of its positive mental and physical effects. Yoga has given me an overall sense of wellbeing and confidence", and another participant suggests, "Yoga is the only exercise l've done that engages the mind as much as the body." This combination of effects may have a greater impact on self-direction or self-regulation than previously understood. Yoga is a unique movement form that incorporates mindfulness meditation, unifying the mind and body. It may be in this connectedness that selfregulation is improved-further research is necessary.

The current research has several limitations; primarily, the participants were predominantly white, highly-educated women; however, several researchsites were in racially, ethnically, and socio-economically diverse communities. Possibly yoga has yet to become a mainstream activity or it may be perceived by some segments of society as a religious undertaking rather than a mind/body movement pattern. Future research is necessary to assess yoga in a variety of populations and age-groups among a larger population. Research is needed among youths to measure the impact of yoga on the development of self-awareness, health behaviors, and exercise participation in academic and community environments. It is also possible that mindfulness meditation coupled with another type of exercise such as cycling would be similarly as productive as yoga and mindfulness meditation. Research is needed to address this possibility in order to further inform the development of productive programming. By design, this exploratory research does not allow for proclamations of cause and effect relationships. It is clear that the factors studied exist in accordance with one another and that human behavior is a complex phenomenon often requiring a mixed-method of inquiry and data collection for deeper understanding.

Finally, it is imperative to develop strategies and interventions that take into consideration the whole person while combating physical inactivity and poor health behaviors. The health of future generations depends on our ability to integrate new evidence-based approaches when battling persistent poor health behaviors.

\section{REFERENCES}

[1] Philippou C, Andreou E, Menelaou N, Hajigeorgiou PH, Papandreou D. Effects of diet and exercise in 337 overweight/obese adults. Hippokratia 2012; 16, 1: 46-50.

[2] Palu AK, West BJ, Jensen J. Noni-based nutritional supplementation and exercise interventions influence body composition. North Am J Med Sci 2011; 3: 552-56. http://dx.doi.org/10.4297/najms.2011.3552

[3] Brinkley T, Wang X, Kume K, Mitsuoka H, Nicklas B. Caloric restriction, aerobic exercise training and soluble lectin-like oxidized LDL receptor-1 levels in overweight and obese postmenopausal women. Int J Obes 2011; 35: 793-99. http://dx.doi.org/10.1038/ijo.2010.199

[4] Flegal K, Carroll M, Ogden C, Curtin L. Prevalence and trends in obesity among US adults. JAMA 2010; 303(3): 23541.

http://dx.doi.org/10.1001/jama.2009.2014

[5] McAuley E, Jerome G, Marquez, D, Elavsky S. Exercise selfefficacy in older adults: Social, affective, and behavioral influences. Soc Behav Med 2003; 1-7.

[6] Annesi J. Relationship between changes in acute exerciseinduced feeling states, self-motivation, and adults' adherence to moderate aerobic exercise. Percept Mot Skills 2002; 94: 425-39.

[7] Spink K, Carron A. Group cohesion and adherence in exercise classes. J Sport Exerc Psychol 1992; 14: 78-86.

[8] Hagger M, Wood C, Stiff C, Chatzisarantis N. The strength model of self-regulation failure and health-related behavior. Health Psychol Rev 2009; 3(2): 208-38. http://dx.doi.org/10.1080/17437190903414387

[9] Marcus B, Eaton C, Harlow L. Self-efficacy, decision making and stages of change: An integrative model of physical exercise. J Appl Soc Psychol 1994; 24: 489-508.

http://dx.doi.org/10.1111/j.1559-1816.1994.tb00595.x

[10] Bandura A. The primacy of self-regulation in health promotion. Appl Psychol: An Int Rev 2005; 54(2): 245-54. http://dx.doi.org/10.1111/j.1464-0597.2005.00208.x

[11] Bishop S, Lau M, Shapiro S, Carlson L, Anderson N Carmody $\mathrm{J}$, et al. Mindfulness: A proposed operational definition. Clin Psychol 2004; 11(3): 230-41.

[12] Bryan S, Zipp G, Parasher R. The effects of yoga on psychosocial variables and exercise adherence: A Randomized Controlled Pilot Study. Altern Ther Health Med 2012; 18(5): 30-39.

[13] Framson C, Kristal A, Schenk J, Littman A, Zeliadt S, Benitez D. Development and validation of the mindful eating questionnaire. J Am Diet Assoc 2009; 109(8): 1439-44. http://dx.doi.org/10.1016/j.jada.2009.05.006

[14] Braun T, Park C, Conboy L. Psychological well-being, health behaviors, and weigh loss among participants in a residential Kripalu yoga-based weight-loss program. Int J Yoga 2012; 22: 9-22.

[15] Gilbert D, Waltz J. Mindfulness and health behaviors. Mindfulness and health behaviors. Mindfulness 2010; 1(4): 227-34.

http://dx.doi.org/10.1007/s12671-010-0032-3

[16] Kristal A, Littman A, Benitez D, White E. Yoga practice is associated with attenuated weight gain in healthy middleaged men and women. Altern Ther Health Med 2005; 11(4): 28-33. 
[17] Dishman R, Steinhardt M. Reliability and concurrent validity for a 7-day recall of physical activity in college students. Med Sci Sports Exerc 1988; 21: 14-25. http://dx.doi.org/10.1249/00005768-198802000-00003

[18] USDA Dietary Guidelines for Americans, http://www.cnpp. usda.gov/Publications/DietaryGuidelines/2010/PolicyDoc/ Chapter4.pdf. Accessed December 1, 2012.
[19] Bellevia A, Larson S, Bottai M, Wolk A, Orsini N. Fruit and vegetable consumption and all-cause mortality: a dose response analyis. Am Jour Clin Nutr 2013; 98(2): 454-59. http://dx.doi.org/10.3945/ajcn.112.056119

Received on 10-10-2013

Accepted on 27-11-2013

Published on 30-12-2013

DOI: http://dx.doi.org/10.6000/1929-5634.2013.02.04.1

(C) 2013 Bryan et al.; Licensee Lifescience Global.

This is an open access article licensed under the terms of the Creative Commons Attribution Non-Commercial License (http://creativecommons.org/licenses/by-nc/3.0/) which permits unrestricted, non-commercial use, distribution and reproduction in any medium, provided the work is properly cited. 